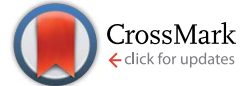

Cite this: Chem. Sci., 2015, 6, 6355

\title{
Copper-catalyzed direct transformation of simple alkynes to alkenyl nitriles via aerobic oxidative $\mathrm{N}$ - incorporation $\uparrow$
}

\author{
Xiaoqiang Huang, ${ }^{a}$ Xinyao $\mathrm{Li}^{\mathrm{a}}$ and Ning Jiao*ab \\ A novel direct transformation of aliphatic terminal alkynes to alkenyl nitriles through the incorporation of a \\ nitrogen atom into the simple hydrocarbons has been reported. The usage of inexpensive copper catalyst, \\ $\mathrm{O}_{2}$ as the sole oxidant, broad substrate scope as well as feasibility for "late-stage modification" make this \\ protocol very promising. Mechanistic studies including DFT calculation demonstrate a novel 1,2-hydride \\ shift process for this novel nitrogenation reaction.
}

Received 12th June 2015

Accepted 20th July 2015

DOI: $10.1039 / \mathrm{c} 5 \mathrm{sc} 02126 \mathrm{j}$

www.rsc.org/chemicalscience

(Scheme 1, C). In this present chemistry: (1) a very simple

\section{Introduction}

Direct transformation of simple and readily available hydrocarbons into complex and high value-added compounds is a long-standing topic in organic synthesis. ${ }^{1}$ Aliphatic alkynes, which are very common and easily accessible building blocks, provide chemists with a fertile testing ground for the construction of complex organic molecules. ${ }^{2-8}$ Many useful reactions of these simple hydrocarbons have been disclosed on the basis of the $\mathrm{C} \equiv \mathrm{C}$ triple bond transformation, such as coupling, ${ }^{3,4}$ addition, ${ }^{5}$ cyclization, ${ }^{6}$ and metathesis reactions. ${ }^{7}$ However, the transformation of simple aliphatic terminal alkynes involving the cleavage of the propargylic $\mathrm{C}\left(\mathrm{sp}^{3}\right)-\mathrm{H}$ bond is still limited. ${ }^{8,9}$

Recently, novel transformation of simple alkynes has been disclosed through the assistance of transition metals. Yamamoto's group significantly developed palladium/acid catalyzed alkylation and hydroamination reaction of internal alkynes with nucleophiles (Scheme 1, A). ${ }^{10}$ By using a Rh(I)/phosphine ligand/ benzoic acid catalyst system, Breit and co-workers pioneeringly achieved the intermolecular coupling of aliphatic terminal alkynes with carboxylic acids and sulfonyl hydrazides under redox-neutral conditions (Scheme 1, B). ${ }^{11}$ Despite these breakthroughs, new catalytic systems and new strategies are highly desirable to disclose novel transformations of aliphatic terminal alkynes.

Herein, we report a novel Cu-catalyzed aerobic oxidative transformation of simple terminal alkynes to alkenyl nitriles

${ }^{a}$ State Key Laboratory of Natural and Biomimetic Drugs, Peking University, School of Pharmaceutical Sciences, Peking University, Xue Yuan Rd. 38, Beijing 100191, China.E-mail: jiaoning@pku.edu.cn

${ }^{b}$ State Key Laboratory of Organometallic Chemistry, Chinese Academy of Sciences, Shanghai 200032, China

$\dagger$ Electronic supplementary information (ESI) available: Characterization data and experimental procedures. See DOI: $10.1039 / \mathrm{c} 5 \mathrm{sc} 02126 \mathrm{j}$ hydrocarbon is successfully converted into an N-containing compound through the incorporation of a nitrogen atom into the substrate; (2) inexpensive Cu-catalyst, the green molecular oxygen oxidant, as well as the broad substrate scope make this protocol very attractive and low-cost; (3) a novel propargylic $\mathrm{C}\left(\mathrm{sp}^{3}\right)-\mathrm{H}$ bond cleavage through $1,2-\mathrm{H}$ shift mechanism is proved. (4) DFT calculation reasonably explains the mechanism and the stereoselectivity of products.

\section{Results and discussion}

We commenced this research by choosing commercially available 5-phenyl-1-pentyne 1a as the model substrate. To our delight, the nitrogenation product $2 \mathrm{a}$ was obtained with azidotrimethylsilane $\left(\mathrm{TMSN}_{3}\right)$ as nitrogen source under coppercatalyzed aerobic conditions (Table 1). After extensive screening of different reaction parameters (see $\mathrm{ESI} \dagger$ for more

(A) Yamamoto's work: Redox-neutral Pd-catalyzed transformation of internal alkynes

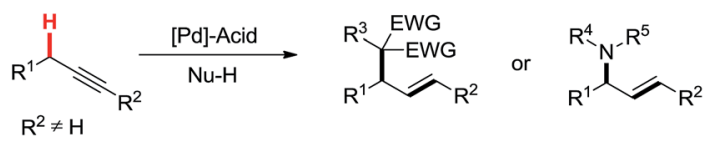

(B) Breit's work: Redox-neutral Rh-catalyzed transformation of terminal alkynes

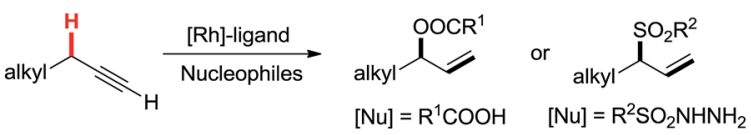

(C) New reaction, new mechanism: Cu-catalyzed aerobic oxidative nitrogenation

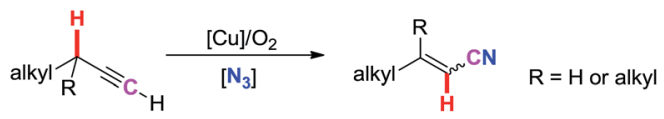

- from simple hydrocarbons to $\mathrm{N}$-containing compounds

Scheme 1 Direct transformation of simple alkynes involving the cleavage of a propargylic $\mathrm{C}\left(\mathrm{sp}^{3}\right)-\mathrm{H}$ bond. 
information), the direct functionalization of $1 \mathbf{a}$ gave $2 \mathbf{a}$ in $78 \%$ yield with a slight $Z$-selectivity $(Z: E=65: 35)$ under the optimized conditions: $\mathrm{TMSN}_{3}$ (2.0 equiv.), $\mathrm{CuBr}(20 \mathrm{~mol} \%)$, pyridine (2.0 equiv.) and $\mathrm{NaOAc}$ (1.0 equiv.), in $\mathrm{PhCl}$ at $90{ }^{\circ} \mathrm{C}$ under $\mathrm{O}_{2}$ (1.0 atm) for $48 \mathrm{~h}$ (entry 1, Table 1 ). As expected, only trace amount of 2 a could be obtained under an argon atmosphere (entry 2). Copper catalyst is essential in this transformation, as no 2a was formed without copper salt or with other common metal salts (such as [Ag], [Fe], [Co], [Mn], see ESI $\dagger$ ). Other copper salts showed lower efficiencies than $\mathrm{CuBr}$ (entries 4-5). Further studies indicated that the reaction did not work in the absence of pyridine (entry 7). DMEDA and L-proline led to no reaction (entries 8-9). Catalytic amount of pyridine only delivered $2 \mathrm{a}$ in $26 \%$ yield (entry 10). It is noteworthy that NaOAc, a very weak base, is the most effective additive while not indispensable for product formation (entries 11-13). ${ }^{12}$ However, great efforts to improve the $Z: E$ ratio of the product did not reach a satisfying result (see $\mathrm{ESI} \dagger$ for more information).

With the optimal conditions in hand, we next investigated the substrate scope of this transformation. This reaction exhibited a good functional group compatibility (Table 2). Longchain-alkyl substituted alkynes were successfully transformed to the corresponding alkenyl nitriles in good yields (2a-2e). Notably, propargylic $3^{\circ} \mathrm{C}-\mathrm{H}$ of $\mathbf{1 f}$ could be cleaved, giving $2 \mathrm{f}$ in $61 \%$ yield. To our satisfaction, terminal alkyne $1 \mathrm{~g}$, bearing a TBDMS protected hydroxyl group, worked well $(2 \mathrm{~g}, 68 \%)$. Remarkably, linkages, including ether bonds (2h-2n) and ester bonds (2o-2q), did not reduce effectiveness. Several functional groups (trifluoromethyl, chlorine, vinyl and thienyl) were well

Table 1 Selected optimization of the reaction conditions ${ }^{a}$

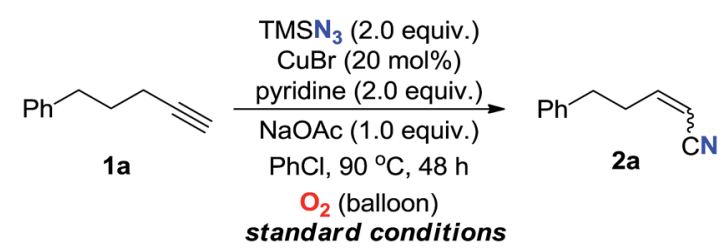

\begin{tabular}{|c|c|c|c|}
\hline Entry & Variation from standard conditions & Yield $^{b}(\%)$ & $Z: E^{c}$ \\
\hline 1 & None & 78 & $63: 35$ \\
\hline 2 & Ar instead of $\mathrm{O}_{2}$ & Trace & - \\
\hline 3 & Without CuBr & 0 & - \\
\hline 4 & $\mathrm{Cu}(\mathrm{OAc})_{2}$ instead of $\mathrm{CuBr}$ & 49 & $69: 31$ \\
\hline 5 & $\mathrm{CuBr}_{2}$ instead of $\mathrm{CuBr}$ & 62 & $67: 33$ \\
\hline 6 & $10 \mathrm{~mol} \% \mathrm{CuBr}$ was employed & 45 & $65: 34$ \\
\hline 7 & Without pyridine & 0 & - \\
\hline 8 & DMEDA instead of pyridine & 0 & - \\
\hline 9 & L-proline instead of pyridine & 0 & - \\
\hline 10 & 0.4 equiv. pyridine was employed & 26 & $69: 31$ \\
\hline 11 & Without NaOAc & 48 & $64: 36$ \\
\hline 12 & LiOAc instead of NaOAc & 48 & $64: 36$ \\
\hline 13 & NaOMe instead of NaOAc & 47 & $67: 33$ \\
\hline \multicolumn{4}{|c|}{$\begin{array}{l}{ }^{a} \text { Standard conditions: } 1 \mathrm{a}(0.40 \mathrm{mmol}), \mathrm{TMSN}_{3}(0.80 \mathrm{mmol}), \mathrm{CuBr}(0.08 \\
\text { mmol }) \text {, pyridine }(0.80 \mathrm{mmol}) \text { and } \mathrm{NaOAc}(0.40 \mathrm{mmol}) \text { in PhCl }(2.0 \\
\mathrm{mL}) \text { under } \mathrm{O}_{2} \text { (balloon) was stirred at } 90{ }^{\circ} \mathrm{C} \text { for } 48 \mathrm{~h} .{ }^{b} \text { Isolated yields. } \\
{ }^{c} \text { Determined by }{ }^{1} \mathrm{H} \text { NMR measurement of the crude mixture. DMEDA } \\
=N, N^{\prime} \text {-dimethyl-1,2-ethanediamine. }\end{array}$} \\
\hline
\end{tabular}

tolerated in the present catalytic system. Furthermore, reasonable yields were obtained for alkynes containing phthalimide and sulfonamide group, respectively (2r-2s). Interestingly, $\mathrm{C}-\mathrm{H}$ bond adjacent to internal ethynyl group was inactive, which leads to the high regioselectivity.

Alkenyl nitriles are not only useful building blocks in synthetic chemistry but also important structure motifs commonly found in drugs. ${ }^{13}$ Moreover, late-stage modification is a highly valuable strategy for medicinal chemistry research. ${ }^{\mathbf{1 4}}$ Therefore, several complex bioactive molecule derivatives were

Table 2 The scope of terminal alkynes ${ }^{a}$

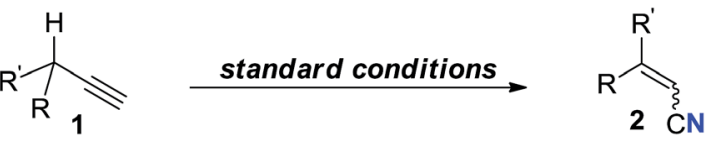

\begin{tabular}{|c|c|c|c|c|}
\hline Entry & & 2 & Yield of $2^{b}(\%)$ & $Z: E^{c}$ \\
\hline 1 & & $n=3$ & $78(2 a)$ & $65: 35$ \\
\hline 2 & $\stackrel{\mathrm{C}}{\mathrm{C}}$ & $n=2$ & $44(2 b)$ & $67: 33$ \\
\hline 3 & & $m=7$ & $76(2 c)$ & $61: 39$ \\
\hline 4 & $\stackrel{\xi}{\mathrm{C} N}$ & $m=6$ & $62(2 d)$ & $66: 34$ \\
\hline 5 & $\hat{\mathrm{C}}_{\mathrm{S}}$ & & $63(2 e)$ & $60:$ \\
\hline 6 & & & $61(2 \mathrm{f})$ & - \\
\hline
\end{tabular}

8

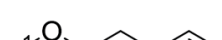

$\mathrm{R}^{1}=$ TBDMS $68(\mathbf{2 g})$

$69: 31$

$\mathrm{R}^{1}=n-\mathrm{C}_{9} \mathrm{H}_{19} \quad 59(2 \mathbf{h})$

$69: 31$

$\mathrm{R}^{2}=\mathrm{C}_{6} \mathrm{H}_{5} \quad 60(2 \mathrm{i})$

$68: 32$

$\mathrm{R}^{2}=4-\mathrm{MeOC}_{6} \mathrm{H}_{4} \quad 50(2 \mathrm{j})$

$69: 31$

$\mathrm{R}^{2}=4-\mathrm{CF}_{3} \mathrm{C}_{6} \mathrm{H}_{4} \quad 66$ (2k)

$\mathrm{R}^{2}=2-\mathrm{ClC}_{6} \mathrm{H}_{4} \quad 71$ (2l)

$\mathrm{R}^{2}=1$-naphth $60(2 \mathrm{~m})$

$\mathrm{R}^{2}=2$-naphth $57(2 \mathbf{n})$

$\mathrm{R}^{3}=\mathrm{Me}$

69 (20)

$\mathrm{R}^{3}=\| \mathrm{s}^{\mathrm{s}}$

40 (2p)

$63: 37$

$66: 34$

$64: 36$

$64: 36$

$69: 31$

$64: 36$

17<smiles>[R3]OC(=O)C(C)(C)/C=C\C#N</smiles>

$\left(\frac{10}{20}\right.$<smiles>N#C/C=C\CCCOC(=O)c1cccs1</smiles>

$73(2 q)$

$66: 34$

18

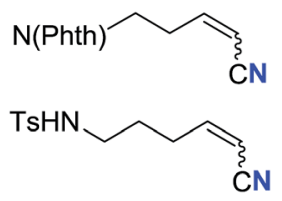

65 (2r)

$69: 31$

19

$61(2 s)$

$70: 30$

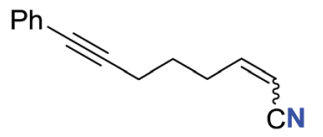

46 (2t)

$66: 34$

\footnotetext{
${ }^{a}$ Standard conditions: see entry 1 , Table $1 .{ }^{b}$ Isolated yields. ${ }^{c}$ Determined by ${ }^{1} \mathrm{H}$ NMR measurement of the crude mixture. ${ }^{d}$ Two portions of $\mathrm{TMSN}_{3}(0.60 \mathrm{mmol})$ were added every $24 \mathrm{~h}$.
} 
submitted to the optimal conditions (Table 3). Natural alcohol derivatives containing ester or ether linkages, such as menthol, borneol, nopol and cholesterol, worked well in the current transformation, generating the corresponding alkenyl nitriles in $49-73 \%$ yield $(\mathbf{4 a}, \mathbf{4 d - f}$ ), respectively. Alkyne $\mathbf{3 b}$ that was prepared from antibacterial metronidazole afforded alkyl alkenyl nitrile $4 \mathrm{~b}$ in $60 \%$ yield. Besides, terminal alkyne with a protected sugar moiety selectively underwent aerobic oxidation, giving nitrogenation product $4 \mathbf{c}$ in $67 \%$ yield. These results demonstrate that the present protocol could be applied in latestage bioactive compound modification.

To gain mechanistic insight into this transformation, some control experiments were conducted under the standard conditions. Allene 5, which could be generated from alkyne 1a, failed to afford nitriles under the present conditions (eqn (1)), indicating a novel mechanism different from Breit's works. ${ }^{\mathbf{1 1}}$ In addition, propargylic azide 6 or allylic azide 7 could not furnish alkenyl nitriles either (eqn (2) and (3)). These results ruled out the possibility of 6 and 7 as intermediates of the transformation. ${ }^{15}$
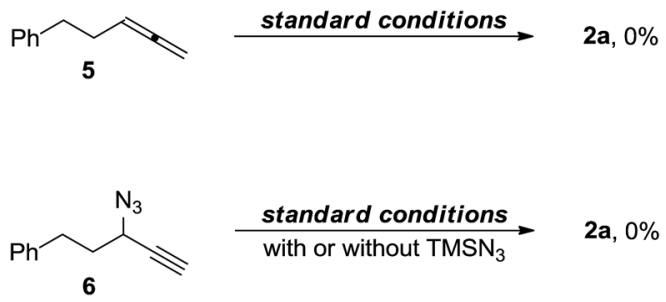

Table 3 The late-stage modification ${ }^{a}$

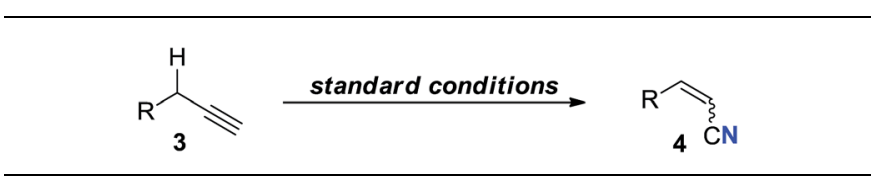

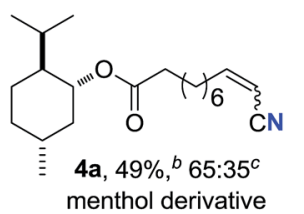

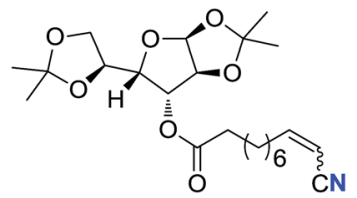

$4 c, 67 \%, 67: 33$ glucofuranose derivative

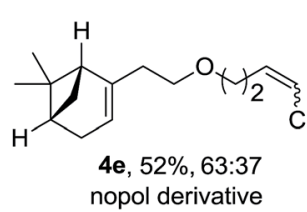
nopol derivative

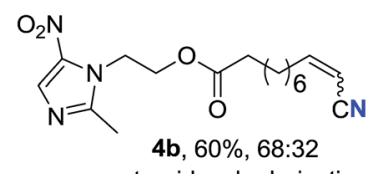

metronidazole derivative

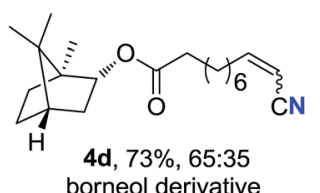
borneol derivative

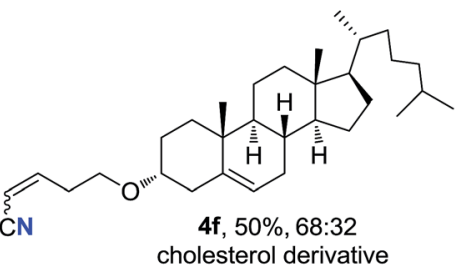

${ }^{a}$ Standard conditions: see entry 1 , Table $1 .{ }^{b}$ Isolated yields.

${ }^{c}$ Determined by ${ }^{1} \mathrm{H}$ NMR measurement of the crude mixture.

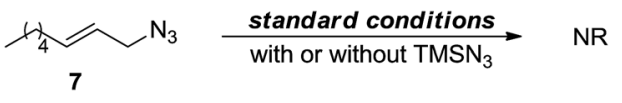

Considering that the current nitrogenation reaction could only be catalyzed by copper salt, and the Glaser-Hay homocoupling product ${ }^{3 a}$ could be detected in some cases, we postulated that copper acetylide might be an intermediate of this reaction. Although, no product was formed employing copper(I)-acetylide 8 as a substrate (eqn (4)), which might due to the aggregation of $8,{ }^{16} 2 \mathrm{c}$ could be obtained in comparative yield when $\mathbf{8}$ was used as a catalyst (eqn (5)). When $\mathrm{C}(\mathrm{sp})-\mathrm{H}$ bond deuterated alkynes 1a-1- $\boldsymbol{d}_{\mathbf{1}}$ was subjected to the reaction, no deuterium was detected in the product, which is in accordance with the existence of copper acetylide species (eqn (6)).
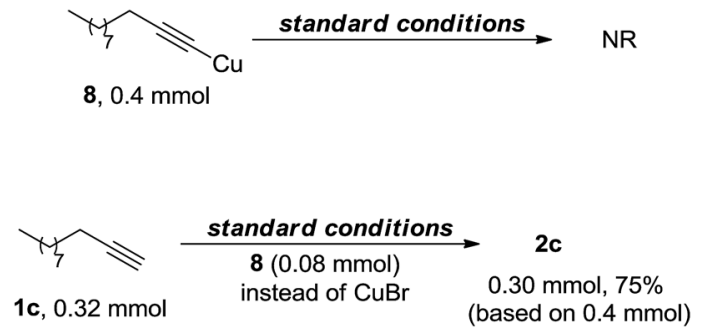

Furthermore, labeling experiment with propargylic $\mathrm{C}-\mathrm{H}$ bond deuterated 1a-3,3- $\boldsymbol{d}_{\mathbf{2}}$ was performed. To our surprise, nearly $100 \%$ incorporation of deuterium at the both $\alpha$ and $\beta$ positions of the nitrile was observed (eqn (7)). Hence, the cleavage of propargylic $\mathrm{C}-\mathrm{H}$ bond might proceed via a 1,2hydride shift. ${ }^{17}$ Then, an intermolecular kinetic isotopic experiment was conducted giving the result of $k_{\mathrm{H}} / k_{\mathrm{D}}=2.2$ (eqn (8)). ${ }^{18}$
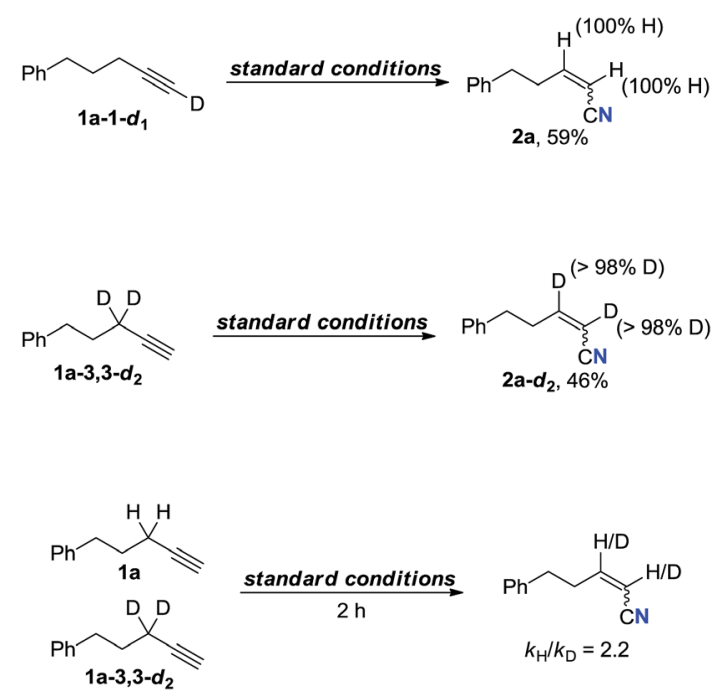

On the basis of all these results and previous reports, a proposed mechanism is depicted in Scheme 2. The reasonable first step is the formation of copper(I)-acetylide intermediate A. ${ }^{16}$ Then, copper triazolide $\mathbf{B}$ formed via Cu-catalyzed azidealkyne cycloaddition (CuAAC) ${ }^{19}$ undergoes ring-opening reaction affording cuprated diazoimine $\mathbf{C}^{20,21}$ The oxidation of $\mathbf{C}$ 
under aerobic conditions with assistance of pyridine gives $\alpha$ diazonitrile $\mathbf{D}$ and regenerates the copper(I) catalyst. ${ }^{22}$ Subsequently, upon loss of dinitrogen $\mathbf{D}$ would afford carbene $\mathbf{E}$ or copper carbene $\mathbf{F}^{23}$ Finally, 1,2-hydride shift of the carbene species generates the alkenyl nitrile. ${ }^{17}$ Alternatively, a mechanism with ethynyl azide could also be possible. Cu-catalyzed aerobic oxidative cross-coupling of terminal alkynes with $\mathrm{TMSN}_{3}$ might generate ethynyl azide $\mathbf{G},{ }^{3 \mathbf{b}, \mathbf{4}}$ which is known to liberate dinitrogen leading to the formation of cyanocarbene species $\mathbf{E}^{24}$

To further explore the stereoselectivity of the reaction, density functional theory (DFT) calculation investigation was carried out (Fig. 1). ${ }^{25}$ After the sequential CuAAC ${ }^{19}$ and ringopening process, ${ }^{\mathbf{2 0 , 2 1}}$ the $\alpha$-diazonitrile INT1 is generated (see ESI $\dagger$ for details). The pyrolysis of INT1 has two pathways. In pathway $A$, the thermal induced release of $\mathrm{N}_{2}$ through TS1 requires an activation free energy of $22.3 \mathrm{kcal} \mathrm{mol}^{-1}$ to give cyanocarbene carbene INT2. Alternatively, INT2 generated from ethynyl azide could not be excluded. ${ }^{24}$ The subsequent 1,2hydride shift process ${ }^{17}$ via $\boldsymbol{Z}$-TS2 and $\boldsymbol{E}$-TS2 almost barrierlessly delivers $\boldsymbol{Z}$-2 and $\boldsymbol{E}$-2, respectively. It is noteworthy that the energy barrier gap between $\boldsymbol{Z}$-TS2 and $\boldsymbol{E}$-TS2 is insignificant (only $0.3 \mathrm{kcal} \mathrm{mol}^{-1}$ ), which might be due to the similar steric hindrance between hydrogen and cyano group. The calculated $Z: E$ ratio of 2 via pathway A is predicted to be $64: 36$, which is qualitatively consistent with the experimentally observed $66: 34$ $Z: E$ ratio for this reaction.

In alternative pathway $\mathrm{B}, \mathrm{Cu}(\mathrm{I})$ catalyst can induce the $\mathrm{Cu}-\mathrm{C}$ bond formation on INT3 with the release of $\mathrm{N}_{2}$ through TS3 in a stepwise manner, which requires an activation free energy of $22.3 \mathrm{kcal} \mathrm{mol}^{-1}$ to form Cu-carbene INT4. ${ }^{23}$ The subsequent 1,2$\mathrm{H}$ shift process ${ }^{17}$ via $\boldsymbol{Z}$-TS4 and $\boldsymbol{E}$-TS4 also barrierlessly furnishes $\boldsymbol{Z}$-2 and $\boldsymbol{E}$-2, respectively. Notably, $\boldsymbol{Z}$-TS4 is also only $0.7 \mathrm{kcal}$ mol $^{-1}$ lower in energy than $\boldsymbol{E}$-TS4, which is corresponding to a $76: 24 Z: E$ ratio of 2 , in good agreement with the experimental observation.

Moreover, $\boldsymbol{E}-2$ is only $0.3 \mathrm{kcal} \mathrm{mol}^{-1}$ lower in energy than $\boldsymbol{Z}$-2, indicating that the $Z$ to $E$ isomerization of alkenyl nitriles 2 is short of driving force thermodynamically. These results could
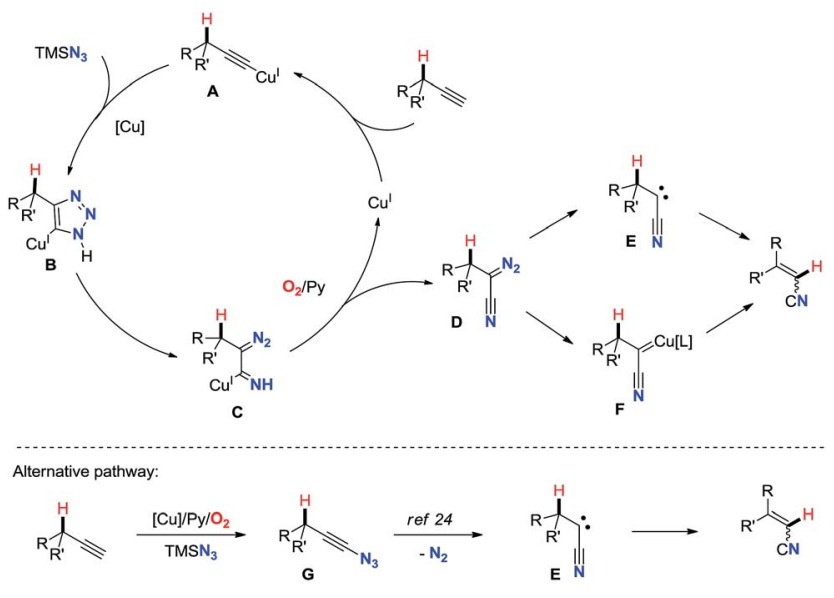

Scheme 2 Proposed mechanism.

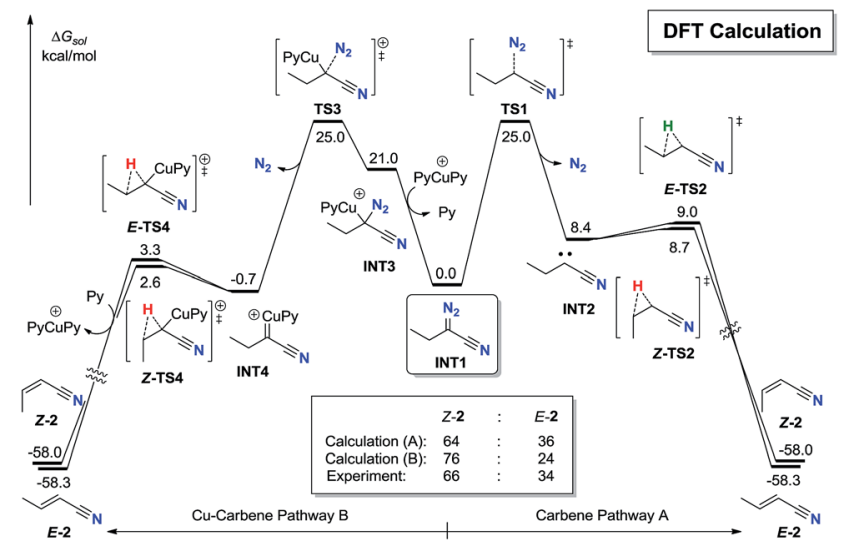

Fig. 1 DFT-computed energy profiles.

explain why the $E: Z$ ratio of the products is so difficult to optimize whether by dynamic or thermodynamic means.

\section{Conclusions}

In conclusion, we have developed a novel copper-catalyzed aerobic oxidative nitrogenation of simple alkyl alkynes via propargylic $\mathrm{C}\left(\mathrm{sp}^{3}\right)-\mathrm{H}$ bond cleavage. A variety of simple and easily accessible alkynes selectively undergo the transformation affording alkenyl nitriles. The late-stage modification of bioactive molecule derivatives makes this protocol very attractive. Mechanism studies indicate a 1,2-hydride shift might be the key step of this novel transformation. DFT calculation reasonably explains the stereoselectivity of products. Further studies on the mechanism and the application are ongoing in our group.

\section{Acknowledgements}

Financial support from National Basic Research Program of China (973 Program) (grant no. 2015CB856600) and National Natural Science Foundation of China (nos 21325206, 21172006), and National Young Top-notch Talent Support Program are greatly appreciated. We thank Zun Wang in this group for reproducing the results of $2 \mathbf{d}$, and $2 \mathrm{~s}$.

\section{Notes and references}

1 (a) K. Godula and D. Sames, Science, 2006, 312, 67; (b) R. G. Bergman, Nature, 2007, 446, 391; (c) T. W. Lyons and M. S. Sanford, Chem. Rev., 2010, 110, 1147; (d) W. R. Gutekunst and P. S. Baran, Chem. Soc. Rev., 2011, 40, 1976.

2 Acetylene Chemistry: Chemistry, Biology, and Material Science, ed. F. Diederich, P. J. Stang and R. R. Tykwinski, Wiley-VCH, Weinheim, 2005.

3 For reviews on coupling reactions of terminal alkynes, see: (a) P. Siemsen, R. C. Livingston and F. Diederich, Angew. Chem., Int. Ed., 2000, 39, 2632; (b) Z. Shao and F. Peng, Angew. Chem., Int. Ed., 2010, 49, 9566; (c) R. Chinchilla and C. Najera, Chem. Soc. Rev., 2011, 40, 5084; (d) C. Zhang, 
N. Li, X. Li, H. Chang, Q. Liu and W. Wei, Youji Huaxue, 2014, 34, 81.

4 For some recent $\mathrm{C}(\mathrm{sp})-\mathrm{H}$ functionalizations of terminal alkynes, see: (a) T. Hamada, X. Ye and S. S. Stahl, J. Am. Chem. Soc., 2008, 130, 833; (b) L. Zhao, O. Baslé and C.-L. Li, Proc. Natl. Acad. Sci. U. S. A., 2009, 106, 4106; (c) T. de Haro and C. Nevado, J. Am. Chem. Soc., 2010, 132, 1512; (d) Y. Wei, H. Zhao, J. Kan, W. Su and M. Hong, J. Am. Chem. Soc., 2010, 132, 2522; (e) M. Chen, X. Zheng, W. Li, J. He and A. Lei, J. Am. Chem. Soc., 2010, 132, 4101; (f) L. Chu and F.-L. Qing, J. Am. Chem. Soc., 2010, 132, 7262; (g) C.-I. Lee, J. Zhou and O. V. Ozerov, J. Am. Chem. Soc., 2013, 135, 3560; (h) A. Harada, Y. Makida, T. Sato, H. Ohmiya and M. Sawamura, J. Am. Chem. Soc., 2014, 136, 13932.

5 For nucleophilic addition to alkynes, see: (a) A. Lumbroso, N. R. Vautravers and B. Breit, Org. Lett., 2010, 12, 5498; (b) B. Xu, W. Wang, L.-P. Liu, J. Han, Z. Jin and G. B. Hammond, J. Organomet. Chem., 2011, 696, 269; (c) T. Mahdi and D. W. Stephan, Angew. Chem., Int. Ed., 2013, 52, 12418; (d) Z. Liu, P. Liao and X. Bi, Org. Lett., 2014, 16, 3668.

6 For some reviews on Click chemistry and other cyclization reactions, see: (a) H. C. Kolb, M. G. Finn and K. B. Sharpless, Angew. Chem., Int. Ed., 2001, 40, 2004; (b) S. K. Mamidyala and M. G. Finn, Chem. Soc. Rev., 2010, 39, 1252; (c) J. E. Hein and V. V. Fokin, Chem. Soc. Rev., 2010, 39, 1302; (d) K. Gilmore and I. V. Alabugin, Chem. Rev., 2011, 111, 6513.

7 For reviews on $\mathrm{C} \equiv \mathrm{C}$ triple bond cleavage, see: (a) A. Fürstner and P. W. Davies, Chem. Commun., 2005, 2307; (b) H. Villar, M. Frings and C. Bolm, Chem. Soc. Rev., 2007, 36, 55; (c) F. Chen, T. Wang and N. Jiao, Chem. Rev., 2014, 114, 8613.

8 For the intramolecular cyclization of functionalized terminal alkynes via propargylic $\mathrm{C}\left(\mathrm{sp}^{3}\right)-\mathrm{H}$ bond cleavage, see: $(a)$ R. D. Grigg, J. W. Rigoli, S. D. Pearce and J. M. Schomaker, Org. Lett., 2012, 14, 280; (b) H. Lebel, C. Trudel and C. Spitz, Chem. Commun., 2012, 48, 7799; (c) H. Lu, C. Li, H. Jiang, C. L. Lizardi and X. P. Zhang, Angew. Chem., Int. Ed., 2014, 53, 7028.

9 For the propargylic oxidation of internal alkynes, see: $(a)$ S. Sakaguchi, T. Takase, T. Iwahama and Y. Ishii, Chem. Commun., 1998, 2037; (b) E. C. McLaughlin and M. P. Doyle, J. Org. Chem., 2008, 73, 4317; (c) Y. Zhao, A. W. T. Ng and Y.-Y. Yeung, Tetrahedron Lett., 2014, 55, 4370. 10 (a) I. Kadota, A. Shibuya, Y. S. Gyoung and Y. Yamamoto, J. Am. Chem. Soc., 1998, 120, 10262; (b) I. Kadota, A. Shibuya, L. M. Lutete and Y. Yamamoto, J. Org. Chem., 1999, 64, 4570; (c) M. Narsireddy and Y. Yamamoto, J. Org. Chem., 2008, 73, 9698.

11 (a) A. Lumbroso, P. Koschker, N. R. Vautravers and B. Breit, J. Am. Chem. Soc., 2011, 133, 2386; (b) A. Lumbroso, N. Abermil and B. Breit, Chem. Sci., 2012, 3, 789; (c) U. Gellrich, A. Meissner, A. Steffani, M. Kahny, H. J. Drexler, D. Heller, D. A. Plattner and B. Breit, J. Am. Chem. Soc., 2014, 136, 1097; (d) K. Xu, V. Khakyzadeh, T. Bury and B. Breit, J. Am.
Chem. Soc., 2014, 136, 16124; (e) P. Koschker, M. Kähny and B. Breit, J. Am. Chem. Soc., 2015, 137, 3131.

$12 \mathrm{NaOAc}$ is widely used in copper-catalyzed aerobic oxidation reactions to promote the efficiency: (a) D. Monguchi, T. Fujiwara, H. Furukawa and A. Mori, Org. Lett., 2009, 11, 1607; (b) A. E. King, B. L. Ryland, T. C. Brunold and S. S. Stahl, Organometallics, 2012, 31, 7948.

13 (a) A. J. Fatiadi, in Preparation and Synthetic Applications of Cyano Compounds, ed. S. Patai and Z. Rappaport, Wiley, New York, 1983; (b) F. F. Fleming and Q. Wang, Chem. Rev., 2003, 103, 2035; (c) F. F. Fleming, L. Yao, P. C. Ravikumar, L. Funk and B. C. Shook, J. Med. Chem., 2010, 53, 7902; (d) J. J. Schafer and W. R. Short, Antiviral Ther., 2012, 17, 1495.

14 (a) E. Lee, A. S. Kamlet, D. C. Powers, C. N. Neumann, G. B. Boursalian, T. Furuya, D. C. Choi, J. M. Hooker and T. Ritter, Science, 2011, 334, 639; (b) D.-H. Wang and J.-Q. Yu, J. Am. Chem. Soc., 2011, 133, 5767; (c) X. Huang, X. Li, M. Zou, S. Song, C. Tang, Y. Yuan and N. Jiao, J. Am. Chem. Soc., 2014, 136, 14858; (d) Z. Zhang and X. Jiang, Org. Lett., 2014, 16, 4400.

15 (a) K. Banert and M. Hagedorn, Angew. Chem., Int. Ed. Engl., 1989, 28, 1675, and references cited therein; (b) J. R. Fotsing and K. Banert, Eur. J. Org. Chem., 2005, 3704.

16 R. Buschbeck, P. J. Low and H. Lang, Coord. Chem. Rev., 2011, 255, 241; also see ref. $6 c$.

17 For selected examples of carbene and metallocarbenoid 1,2hydride shift, see: (a) D. F. Taber, R. J. Herr, S. K. Pack and J. M. Geremia, J. Org. Chem., 1996, 61, 2908; (b) N. Jiang, Z. Qu and J. Wang, Org. Lett., 2001, 3, 2989; (c) V. K. Aggarwal, C. G. Sheldon, G. J. Macdonald and W. P. Martin, J. Am. Chem. Soc., 2002, 124, 10300; (d) J. A. May and B. M. Stoltz, J. Am. Chem. Soc., 2002, 124, 12426; (e) K. S. Graves, D. M. Thamattoor and P. R. Rablen, J. Org. Chem., 2011, 76, 1584.

18 E. M. Simmons and J. F. Hartwig, Angew. Chem., Int. Ed., 2012, 51, 3066.

19 (a) M. Ahlquist and V. V. Fokin, Organometallics, 2007, 26, 4389; (b) M. Meldal and C. W. Tornøe, Chem. Rev., 2008, 108, 2952; (c) B. T. Worrell, J. A. Malik and V. V. Fokin, Science, 2013, 340, 457; also see ref. 6.

20 For reviews about reactions of metallocarbenes derived from 1,2,3-triazoles, see: (a) A. V. Gulevich and V. Gevorgyan, Angew. Chem., Int. Ed., 2013, 52, 1371; for selected examples catalyzed by Cu-catalyst, see: $(b)$ I. Bae, H. Han and S. Chang, J. Am. Chem. Soc., 2005, 127, 2038; (c) M. P. Cassidy, J. Raushel and V. V. Fokin, Angew. Chem., Int. Ed., 2006, 45, 3154; (d) E. J. Yoo, M. Ahlquist, S. H. Kim, I. Bae, V. V. Fokin, K. B. Sharpless and S. Chang, Angew. Chem., Int. Ed., 2007, 46, 1730; (e) H.-D. Xu, Z.-H. Jia, K. Xu, M. Han, S.-N. Jiang, J. Cao, J.-C. Wang and M.-H. Shen, Angew. Chem., Int. Ed., 2014, 53, 9284; $(f)$ V. Helan, A. Gulevich and V. Gevorgyan, Chem. Sci., 2015, 6, 1928.

21 For selected examples on Rh-catalyzed ring expansion and rearrangement involving azavinyl carbenes, see: (a) T. Miura, Y. Funakoshi, M. Morimoto, T. Biyajima and 
M. Murakami, J. Am. Chem. Soc., 2012, 134, 17440; (b) N. Selander, B. T. Worrell and V. V. Fokin, Angew. Chem., Int. Ed., 2012, 51, 13054; (c) T. Miura, Y. Funakoshi and M. Murakami, J. Am. Chem. Soc., 2014, 136, 2272; (d) Y. Shi, A. V. Gulevich and V. Gevorgyan, Angew. Chem., Int. Ed., 2014, 53, 14191; (e) T. Miura, T. Nakamuro, C.-J. Liang and M. Murakami, J. Am. Chem. Soc., 2014, 136, 15905.

22 L. M. Dornan, Q. Cao, J. C. A. Flanagan, J. J. Crawford, M. J. Cook and M. J. Muldoon, Chem. Commun., 2013, 49, 6030 .

23 For formation of copper carbenes from diazo compounds, see: (a) W. Kirmse, Angew. Chem., Int. Ed., 2003, 42, 1088; (b) Y. Liang, H. Zhou and Z.-X. Yu, J. Am. Chem. Soc., 2009,
131, 17783; (c) X. Zhao, Y. Zhang and J. Wang, Chem. Commun., 2012, 48, 10162.

24 For references about alkynyl azides, see: (a) K. Banert, M. Hagedorn, J. Wutke, P. Ecorchard, D. Schaarschmidt and H. Lang, Chem. Commun., 2010, 46, 4058; (b) I. F. D. Hyatt and M. P. Croatt, Angew. Chem., Int. Ed., 2012, 51, 7511; (c) K. Banert, R. Arnold, M. Hagedorn, P. Thoss and A. A. Auer, Angew. Chem., Int. Ed., 2012, 51, 7515.

25 All of the geometry optimizations and frequency calculations were performed at B3LYP(CPCM)/SDD-6-311+G(d,p)// B3LYP(gas)/SDD-6-31G(d) level in Gaussian 09 (M. J. Frisch, et al.). Computational details and references are given in the ESI $\dagger$. 